\title{
Microstructural Transformation in a Root Pass of Superduplex Stainless Steel Multipass Welding
}

\author{
Doris Ivette Villalobos-Vera ${ }^{a}$, Ivan Mendoza-Bravo ${ }^{a}$ \\ ${ }^{a}$ Department of Mechanical Engineering, Instituto Tecnológico de Veracruz, Calz. Miguel Angel de \\ Quevedo, 2779, Veracruz, Veracruz, México
}

Received: July 6, 2016; Revised: October 31, 2016; Accepted: November 21, 2016

\begin{abstract}
The microstructure of the root pass in a superduplex stainless steel multipass welding was investigated. Results showed that the welding metal has an austenite matrix with particles of sigma phase formed in the ferrite/austenite interface and intragranularly.Eventhough the filler metal is intended to keep the phase balance after welding, the welding metal presented a considerable decrease in the ferrite content and a high proportion of sigma phase. Despite the exposition to thermal cycles on every pass, the heat affected zone presented a microstructure consisting of ferrite and austenite with a small proportion of sigma phase. Therefore, the thermal cycles of every welding pass allowed the decomposition of ferrite into austenite and sigma phase in points close to the heat source, changing the final microstructure.
\end{abstract}

Keywords: duplex stainless steel, thermal cycles, sigma phase, multipass welding

\section{Introduction}

Superduplex stainless steels have been used in the chemical and petrochemical industries since they can be formed and welded with standard equipment and techniques ${ }^{1}$. However, they are susceptible to the formation of secondary phases like sigma $(\sigma)$, $\operatorname{chi}(\chi), \gamma_{2}, \mathrm{M}_{23} \mathrm{C}_{6}$ and $\mathrm{Cr}_{2} \mathrm{~N}^{2,3}$ when the material is exposed to the temperature range of $300^{\circ} \mathrm{C}-1000^{\circ} \mathrm{C}^{4}$. During a single pass welding, the material experience a thermal cycle consisting of a very rapid heating to a peak temperature and a fast cooling to room temperature. On the other hand, in a multipass welding both the heat affected zone and the welding metal of the root pass are exposed to the thermal cycles corresponding to the deposition of the subsequent passes. This cause a considerable reheating which can promote an unbalanced microstructure of ferrite and austenite because the temperature range for the formation of secondary phases through the decomposition of ferrite can be reached. For duplex alloys, the precipitation of sigma phase takes place during cooling in the temperature range of $1200^{\circ} \mathrm{C}-800^{\circ} \mathrm{C}$ as well as the formation of austenite through the decomposition of ferrite to sigma phase and austenite. This means that the time in that temperature range is an important factor to consider in the welding of duplex alloys since sigma phase can precipitate from ferrite either in the heat affected zone or the welding metal. Additionally, the cooling rate plays an important role. A slow cooling rate of the weld promotes a favorable high austenite fraction, but can also give coarser grains and precipitation of brittle intermetallic phases such as sigma ${ }^{5}$. Sigma phase depends on the temperature and time. Aging between $650^{\circ} \mathrm{C}$ and $950^{\circ} \mathrm{C}$ promotes the formation of sigma phase by eutectoid decomposition of ferrite or by nucleation and growth from ferrite and austenite $\mathrm{e}^{6,7}$. Solution annealed at $1080^{\circ} \mathrm{C}$ and water quenched showed the presence of sigma phase in the ferrite/austenite interfaces ${ }^{8}$.

Therefore, the final microstructure in the welding metal and the heat affected zone, are greatly dependent on the heating and cooling rates ${ }^{9}$ and the peak temperature reached. Eventhough multipass welding is more common during the practical industrial fabrication especially for the plate or pipe of middle thickness ${ }^{10}$, investigations on the heat affected zone and the welding metal of multipass welding is scarcely reported. This work, focused on the phase transformations in the heat affected zone and welding metal of a superduplex stainles steel as a result of the thermal cycles in the root pass.

\section{Experimental Procedure}

UNS S32750 superduplex stainless steels plate with dimension of $360 \mathrm{~mm} \times 80 \mathrm{~mm} \times 6 \mathrm{~mm}$ of thickness was welded using GMAW process. Chemical composition of the superduplex stainless steel and the filler metal is shown in Table 1 and welding parameters in Table 2. These parameters were chosen based on trials performed on some superduplex stainles steel plates in order to know the adecuate current, voltage and welding speed for joining the plates.

The temperature distribution in the heat affected zone corresponding to the root pass was calculated using a heatflow equation for a thick plate model shown in equation $(1)^{11}$ and the cooling time between $1200^{\circ} \mathrm{C}$ and $800^{\circ} \mathrm{C}\left(\Delta \mathrm{t}_{12 / 8}\right)$ was calculated according to equation $(2)^{5}$.

$$
T p-T_{o}=\left(\frac{2}{\pi e}\right)\left(\frac{q / \nu}{\rho \varsigma r^{2}}\right)
$$




$$
\Delta t_{12 / 8}=\Delta t_{8 / 5} \frac{\frac{1}{1073-T_{O}}}{\frac{1}{773-T_{O}}-\frac{\frac{1}{1473-T_{O}}}{1}}
$$

where $T p$ is the peak temperature of the thermal cycle, $T_{0}$ is the initial temperature prior to welding, $e$ is the base of natural logarithms, $q$ is the heat input, $v$ is the welding speed $r$ is the distance from the fusion zone. For duplex stainless steel, $\rho$ is the specific heat equal to $480 \mathrm{~J} / \mathrm{kg}^{\circ} \mathrm{C}$, c is the density equal to $7800 \mathrm{~kg} / \mathrm{m}^{3}$ and $r$ is the distance from the fusion zone. The thermal cycles were calculated for point $A$, in the range of $7 \mathrm{~mm}$ to $10 \mathrm{~mm}$ from the fusion zone as follows:

For $r=7 \mathrm{~mm}$ from the fusion zone:

$$
T p-25^{\circ} \mathrm{C}=.2344(4891.3)=1146^{\circ} \mathrm{C}+25^{\circ} \mathrm{C}=1177^{\circ} \mathrm{C}
$$

The microstructural characterization was carried out by standard techniques including grinding with $\mathrm{SiC}$ paper and polishing with 1, 3 and 9 microns diamond paste. To reveal the microstructure, the samples were etched with $\mathrm{NaOH}$ which attacks ferrite, austenite and sigma phase ${ }^{12}$. The samples were analyzed through optical microscopy. The percentage of phases was calculated using an image analyzer and the microanalysis was performed by EDX.

\section{Results and Discussion}

The microstructure of the as-received condition in Figure 1 depicts a $\approx 54 \%$ ferrite and $\approx 46 \%$ austenite with grains oriented to the rolling direction resulting in a balanced microstructure formed by islands of austenite in a ferrite matrix.

\subsection{Welding Metal}

Two microstructures are observed in the welding metal corresponding to the root pass in Figure 2 since the phase balance of the superduplex stainless steel is disturbed when the material experiences high temperatures and fast

Table 1. Chemical composition of materials

\begin{tabular}{lccccccc}
\hline Material & $\mathrm{C}$ & $\mathrm{Si}$ & $\mathrm{Mn}$ & $\mathrm{Ni}$ & $\mathrm{Cr}$ & $\mathrm{Mo}$ & $\mathrm{N}$ \\
\hline UNS & 0.03 & 0.407 & 0.882 & 5.78 & 23.40 & 3.238 & 0.27 \\
S32750 & & & & & & & \\
ER & 0.04 & 0.490 & 0.509 & 7.32 & 21.72 & 3.009 & 0.25 \\
25.10.4L & & & & & & & \\
\hline
\end{tabular}

Table 2. Welding parameters

\begin{tabular}{lcccc}
\hline Sample & $\begin{array}{c}\text { Protection } \\
\text { gas }\end{array}$ & $\begin{array}{c}\text { Current } \\
(\mathrm{A})\end{array}$ & $\begin{array}{c}\text { Voltage } \\
(\mathrm{V})\end{array}$ & $\begin{array}{c}\text { Welding } \\
\text { speed } \\
(\mathrm{mm} / \mathrm{s})\end{array}$ \\
\hline $\mathrm{S} 1$ & $\mathrm{Ar}$ & 300 & 30 & 3 \\
\hline
\end{tabular}

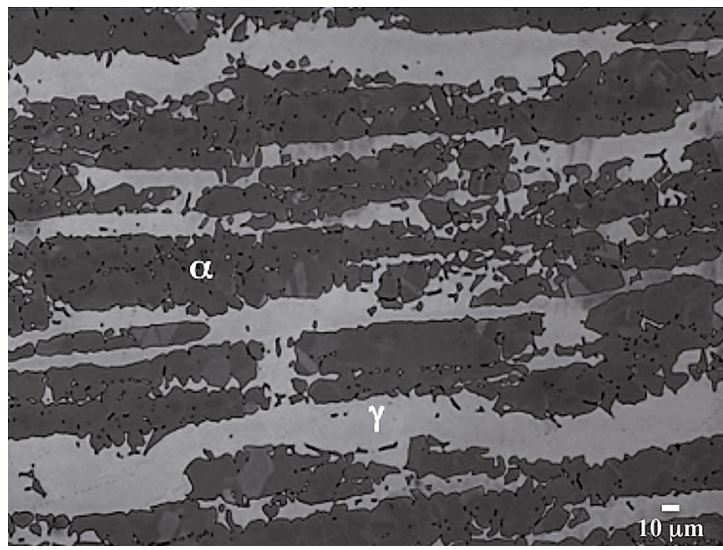

Figure 1. Microstructure of UNS S32750 superduplex stainless steel in the as-received condition.

or slow cooling rates such as in a multipass welding. The first microstructure in Figure 2a-2b, which is mostly present all over the welding metal, showed a significant decrease in the ferrite $(\approx 15 \%)$ compared to the base material due to the reheating promoted by the subsequent deposition of the welding passes. The high proportion of austenite $(\approx 73 \%)$ is uniformely distributed and a substantial precipitation of sigma phase particles $(\approx 12 \%)$ is noticeable in the ferrite/ austenite interface and within the ferrite. In some areas there is evidence of the complete dissolution of the ferrite due to the formation of sigma.

The second microstructure in Figure $2 \mathrm{c}$ is located in some isolated areas in the welding metal, showing the formation of Widmanstätten austenite. Along with the ferrite and austenite, the presence of secondary austenite is evident as well as some particles of sigma phase in the ferrite/austenite interface and the growth of sigma phase into the ferrite. The final microstructure in the welding metal is heavily dependent on diffusion ${ }^{12}$ and the chemical composition of the filler metal plays an important role. Duplex alloys solidify as $100 \%$ ferrite approximately ${ }^{13}$ and the welding metal of a single pass welding can consist in more ferrite than austenite. In order to restore the phase balance, weld filler materials are usually overalloyed with $2-4 \%$ more Ni than in the base material ${ }^{14}$. During welding, the disolution of austenite takes place during heating. At the end of solidification and below the ferrite solvus, the austenite begins to nucleate and grow along the ferrite grain boundaries and within the ferrite grains ${ }^{12}$. It can be assumed that $\mathrm{Ni}$ promotes the austenite to nucleate at a temperature close to ferrite solvus in the ferrite grains boundaries and then intragranularly, resulting in a high proportion of austenite in the welding metal. Evenmore, it is considered that $\mathrm{Ni}$ influences the ferrite-austenite transformation since it can increase the temperature of transformation during cooling ${ }^{15}$.

The chemical compositions of ferrite, austenite and sigma phase are presented in Table 3. Sigma phase is richer in $\mathrm{Cr}$, 

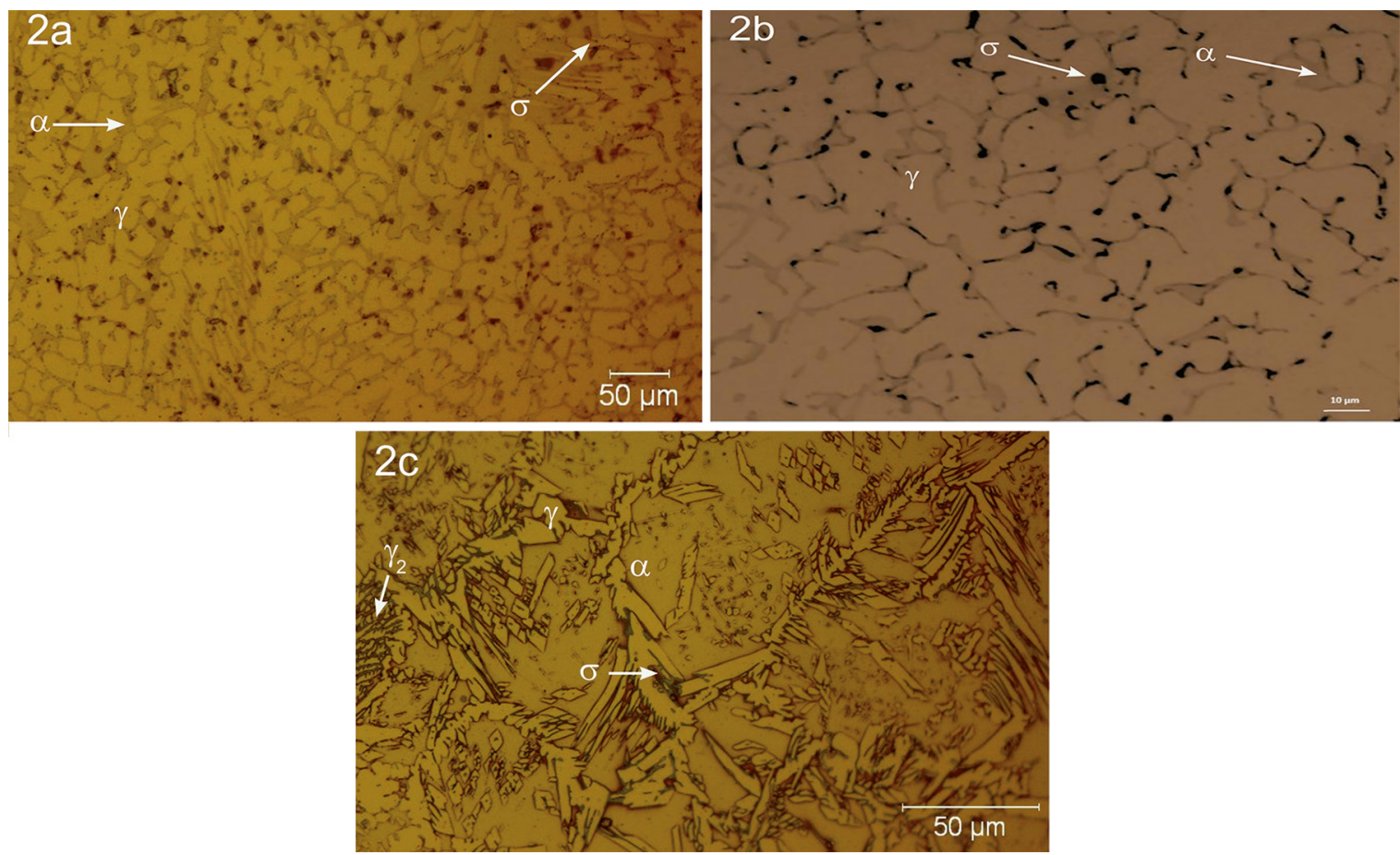

Figure 2. Microstructure of the welding metal corresponding to the root pass with the presence of austenite, ferrite and sigma phase.

Table 3. Chemical composition of ferrite, austenite and sigma phase in the welding metal

\begin{tabular}{lccccc}
\hline Phase & $\mathrm{Cr}$ & $\mathrm{Fe}$ & $\mathrm{Ni}$ & $\mathrm{Mo}$ & $\mathrm{Si}$ \\
\hline$\gamma$ & 18.1 & 64.2 & 7.2 & 2.39 & 0.69 \\
$\delta$ & 16.4 & 56.4 & 7.8 & 2.4 & 1.09 \\
$\sigma$ & 23.2 & 47.9 & 5.4 & 7.4 & 1.18 \\
\hline
\end{tabular}

Mo and Si when compared to the austenite and slightly richer compared to the ferrite. The hight amount of $\mathrm{Cr}$ and $\mathrm{Mo}$ of sigma phase, indicates that those elements are responsible for the formation of sigma since the rate of $\mathrm{Cr}$ and $\mathrm{Mo}$ diffusion in ferrite is almost 100 times greater than that in austenite ${ }^{16}$. The proportion of sigma phase in the welding metal can be related to the difussion of the ferrite-stabilizing elements $\mathrm{Cr}$ and $\mathrm{Mo}^{17}$ and the reheating experienced due to the subsequent deposition of welding passes. The reheated welding metal in a multipass welding continually experience multiple exposures to the temperature range where sigma phase form. This results in the total dissolution of ferrite, first due to sigma precipitation occurs in the ferrite ${ }^{18,19}$ where the difussion of chromium and molybdenum takes place from the ferrite to the ferrite/austenite interfaces ${ }^{20}$ and secondly, the nuclei of sigma phase then grow into the adjacent ferrite grains ${ }^{21}$. If the material keeps the ideal condition of temperature and time, sigma phase will grow until the complete dissolution of ferrite.

\subsection{Heat-Affected Zone}

According to the heat distribution calculation in Figure 3 , the peak temperature in the heat affected zone in point $\mathrm{A}$ is $1177^{\circ} \mathrm{C}$ at $7 \mathrm{~mm}$ from the heat source and $904^{\circ} \mathrm{C}$ at $8 \mathrm{~mm}$ from the heat source. Beside this, the cooling time between $1200^{\circ} \mathrm{C}-800^{\circ} \mathrm{C}$ is $\approx 3 \mathrm{~s}$. This means that the temperature where sigma phase forms is reached in the first pass welding and the time is enough to promote its formation. Since it is a multipass welding, the heat affected zone experiences reheating in the same points and a slow cooling rate. During heating, the austenite to ferrite transformation takes place. Then, the microstructure is fully ferritic having a grain growth and finally, during cooling the austenite reforms and some precipitation occurs ${ }^{12}$. Since there is no fusion involved, the final microstructure of ferrite and austenite is more balanced compared to the welding metal.

Since the heat affected zone near the fusion zone is exposed to the thermal cycles of the root, filler and cover passes, the resulting microstructure in Figure 4a shows the presence of ferrite $(\approx 40 \% \pm 1.13)$, austenite $(\approx 57 \% \% \pm 1.02)$ and small particles of sigma phase $(\approx 1 \% \% \pm .21)$ in the ferrite/ austenite interface as well as some islands of secondary austenite $(\approx 2 \% \% \pm .37)$. On the other hand, the microstructure in Figure $4 \mathrm{~b}$ shows only ferrite, austenite and sigma phase. The temperature in the root pass due to the reheating allowed the formation of sigma phase through the difussion of $\mathrm{Cr}$ to the ferrite/austenite interfaces ${ }^{22}$ since they are high energy zones which have been regarded as the favorable site for the heterogeneous nucleation of sigma phase ${ }^{18}$. Additonally, the cooling time plays an important role on the sigma phase formation. With rapid cooling, the ferrite/austenite reaction is suppressed ${ }^{23}$ and the amount of ferrite in the heat affected zone and the welding metal will be high. However, with slow 


\section{ROOT PASS}

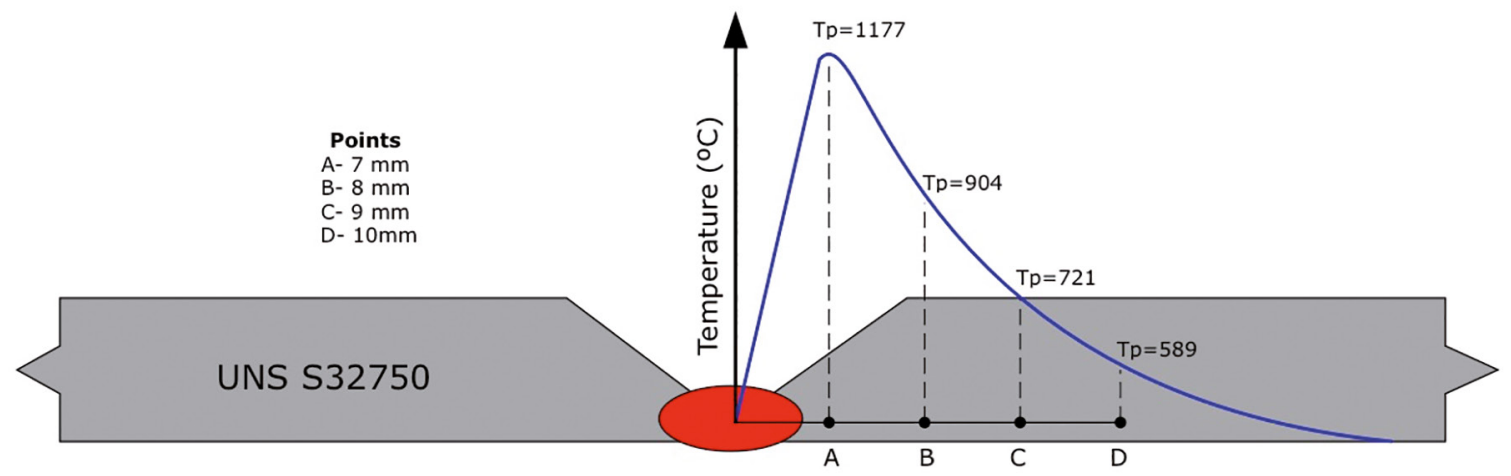

Figure 3. Heat distribution in the root pass of the welding.
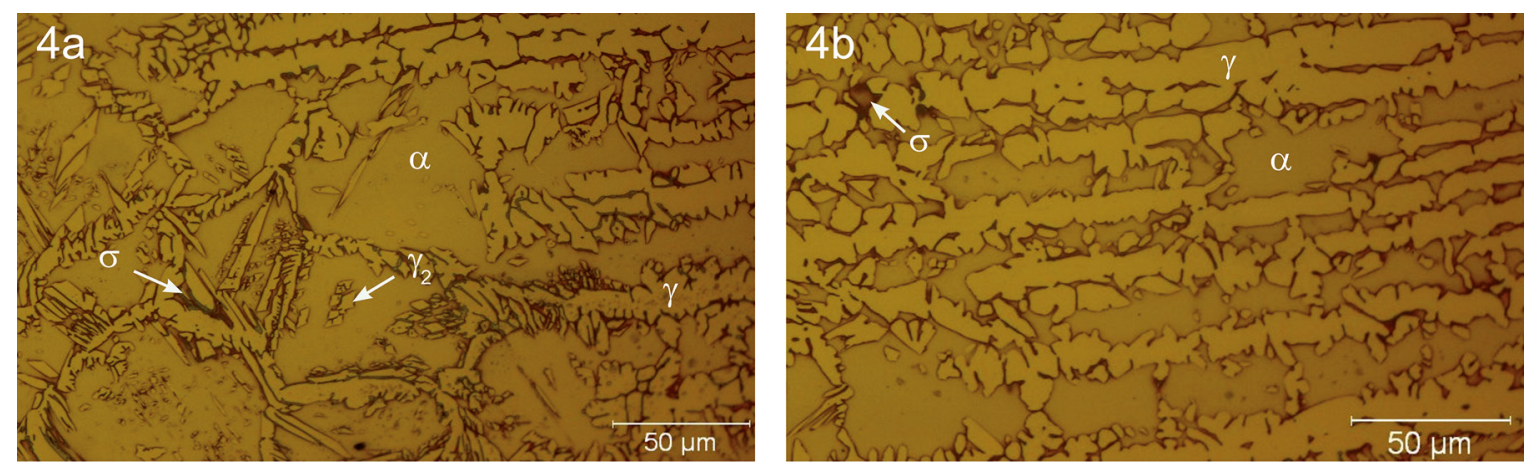

Figure 4. Microstructure of the heat affected zone corresponding to the root pass: a) austenite, ferrite, sigma phase and secondary austenite; b) austenite, ferrite and sigma phase.

cooling, the ferrite/austenite reaction takes place, allowing the austenite to grow from ferrite but also the sigma phase can nucleate and grow from the ferrite. A slow cooling allows the difussion of $\mathrm{Cr}$ and Mo to the ferrite/austenite interfaces, promoting the formation of sigma phase isothermically. It has been reported that a multipass welding can cause diffusional transformation of ferrite to austenite in reheated areas, as well as precipitation of intermetallic phases if the temperature of the reheated zone is approximately $700-800^{\circ} \mathrm{C}^{5}$. Chemical composition of phases in the heat affected zone are presented in Table 4. Sigma phase is richer in $\mathrm{Cr}$ and Mo compared to the ferrite, indicating that those elements forming sigma come from the ferrite. On the other hand, it can be observed that the amount of $\mathrm{Cr}$ and Mo is bigger in the austenite compared to the ferrite probably due to the permanence at high temperatures allowing the diffusion of $\mathrm{Cr}$ and Mo either to the austenite or sigma.

\section{Conclusions}

The results from this study suggest that the reheating in a multipass welding promote the formation of sigma phase in the heat affected zone and the welding metal. Eventhough the chemical composition of both the filler
Table 4. Chemical composition of ferrite, austenite and sigma phase in the heat affected zone

\begin{tabular}{lccccc}
\hline Phase & $\mathrm{Cr}$ & $\mathrm{Fe}$ & $\mathrm{Ni}$ & $\mathrm{Mo}$ & $\mathrm{Si}$ \\
\hline$\gamma$ & 21.83 & 58.21 & 8.28 & 3.03 & 0.44 \\
$\delta$ & 20.37 & 59.68 & 6.87 & 2.66 & 0.39 \\
$\sigma$ & 22.56 & 58.06 & 8.55 & 3.27 & 0.73 \\
\hline
\end{tabular}

metal and metal base is well balanced in order to promote the ferrite/austenite microstructure after welding, thermal cycles can involve peak temperatures that fall in the temperature range for sigma phase formation. It can be assumed that the cooling time from the peak temperature allow the ferrite to decompose through the difussion of $\mathrm{Cr}$ and Mo into the ferrite/austenite interfaces causing the formation of sigma phase and having enough time to grow into the center of the ferrite grain resulting in a complete dissolution of ferrite phase.

\section{Acknowledgements}

The author would like to acknowledge CONACYT for the financial support to perform this investigation and SANDVIK México for donating the material. 


\section{References}

1. Cortie MB, Jackson EMLEM. Simulation of the precipitation of sigma phase in duplex stainless steels. Metallurgical and Materials Transactions A. 1997;28(12):2477-2484.

2. Merino C, Hierro P, Fernandez P, Fosca C. Kinetic study of eutectoid transformation to $24 \% \mathrm{Cr} / 7 \%$ Ni duplex stainless steel. In: Proceedings of the $4^{\text {th }}$ International Conference on Duplex Stainless Steels. Volume 1. Paper 41; 1994; Glasgow, Scotland.

3. Huang CS, Shih CC. Effects of nitrogen and high temperature aging on $\sigma$ phase precipitation of duplex stainless steel. Materials Science and Engineering: A. 2005;402(1-2):66-75.

4. Sathirachinda N, Pettersson R, Wessman S, Kivisäkk U, Pan J. Scanning Kelvin probe force microscopy study of chromium nitrides in 2507 super duplex stainless Steel--Implications and limitations. Electrochimica Acta. 2011;56(4):1792-1798.

5. Sieurin H, Sandström R. Austenite reformation in the heat-affected zone of duplex stainless steel 2205. Materials Science and Engineering: A. 2006;418(1-2):250-256.

6. Magnabosco R, Alonso-Falleiros N. Pit morphology and its relation to microstructure of $850^{\circ} \mathrm{C}$ aged duplex stainless steel. Corrosion. 2005;61(2):130-136.

7. Sieurin H, Sandström R. Sigma phase precipitation in duplex stainless steel 2205. Materials Science and Engineering: A. 2007;444(1-2):271-276.

8. Martins M, Casteletti LC. Sigma phase morphologies in cast and aged super duplex stainless steel. Materials Characterization. 2009;60(8):792-795.

9. Poorhaydari K, Patchett BM, Ivey DG. Estimation of cooling rate in the welding of plates with intermediate thickness. Welding Journal. 2005;84(10):149s-155s.

10. Tan H, Wang Z, Jiang Y, Yang Y, Deng B, Song H, Li J. Influence of welding thermal cycles on microstructure and pitting corrosion resistance of 2304 duplex stainless steels. Corrosion Science. 2012;55:368-377.
11. Easterling K. Introduction to the Physical Metallurgy of Welding. $2^{\text {nd }}$ ed. Oxford: Butterworth-Heinemann; 1992.

12. Lippold JC, Kotecki DJ. Welding Metallurgy and Weldability of Stainless Steels. Hoboken: Wiley; 2005. 376 p.

13. Stevens KJ. Fatigue performance and microanalysis of heat treated 2205 duplex stainless steel. Materials Science and Technology. 1999;15(8):903-908.

14. Muthupandi V, Bala Srinivasan P, Seshadri SK, Sundaresan S. Effect of weld metal chemistry and heat input on the structure and properties of duplex stainless steel welds. Materials Science and Engineering: A. 2003;358(1-2):9-16.

15. Davis JR. ASM Specialty Handbook. Stainless Steels. Materials Park: ASM International; 1994.

16. Padilha AF, Rios PR. Decomposition of Austenite in Austenitic Stainless Steels. ISIJ International. 2002;42(4):325-337.

17. Nishimoto K, Saida K, Katsuyama O. Prediction of Sigma Phase Precipitation in Super Duplex Stainless Steel Weldments. Welding in the World. 2006;50(3):13-28.

18. Chen TH, Yang JR. Effects of solution treatment and continuous cooling on $\sigma$-phase precipitation in a 2205 duplex stainless steel. Materials Science and Engineering: A. 2001;311(1-2):28-41.

19. Duprez L, De Cooman BC,Akdut N. Redistribution of the substitutional elements $\mathrm{Cr}$, Mo and $\mathrm{Ni}$ during $\sigma$ and $\chi$ phase formation in a duplex stainless steel. Steel Research International. 2001;72(8):311-316.

20. Solomon HD, Devine TM. Duplex stainless steels: a tale of two phases. Metals Park: American Society for Metals; 1982.

21. Kuroda T, Nakade K, Ikeuchi K. Precipitation behavior of sigma phase in duplex stainless steels and weld metals. Welding Reasearch Abroad. 2001;47(2):2-7.

22. Magnabosco R. Kinetics of sigma phase formation in a Duplex Stainless Steel. Materials Research. 2009;12(3):321-327.

23. Terasaki T, Gooch TG. Prediction of Cooling Time for FerriteAustenite Transformation in Duplex Stainless Steel. ISIJ International. 1995;35(10):1272-1276. 